\title{
STAR Facility Tritium Accountancy
}

\section{8th International Conference on Tritium Science and Technology}

\author{
R. J. Pawelko \\ J. P. Sharpe \\ B. J. Denny
}

September 2007

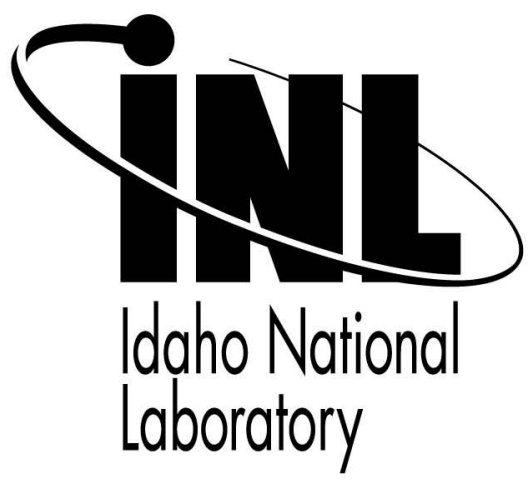

This is a preprint of a paper intended for publication in a journal or proceedings. Since changes may be made before publication, this preprint should not be cited or reproduced without permission of the author. This document was prepared as an account of work sponsored by an agency of the United States Government. Neither the United States Government nor any agency thereof, or any of their employees, makes any warranty, expressed or implied, or assumes any legal liability or responsibility for any third party's use, or the results of such use, of any information, apparatus, product or process disclosed in this report, or represents that its use by such third party would not infringe privately owned rights. The views expressed in this paper are not necessarily those of the United States Government or the sponsoring agency. 


\title{
STAR FACILITY TRITIUM ACCOUNTANCY
}

\author{
R. J. Pawelko, J. P. Sharpe, B. J. Denny \\ Idaho National Laboratory, P.O. Box 1625, Idaho Falls, Idaho 83415
}

The Safety and Tritium Applied Research (STAR) facility has been established to provide a laboratory infrastructure for the fusion community to study tritium science associated with the development of safe fusion energy and other technologies. STAR is a radiological facility with an administrative total tritium inventory limit of $1.5 \mathrm{~g}(14,429 \mathrm{Ci})$ [1]. Research studies with moderate tritium quantities and various radionuclides are performed in STAR. Successful operation of the STAR facility requires the ability to receive, inventory, store, dispense tritium to experiments, and to dispose of tritiated waste while accurately monitoring the tritium inventory in the facility.

This paper describes tritium accountancy in the STAR facility. A primary accountancy instrument is the tritium Storage and Assay System (SAS): a system designed to receive, assay, store, and dispense tritium to experiments. Presented are the methods used to calibrate and operate the SAS. Accountancy processes utilizing the Tritium Cleanup System (TCS), and the Stack Tritium Monitoring System (STMS) are also discussed. Also presented are the equations used to quantify the amount of tritium being received into the facility, transferred to experiments, and removed from the facility. Finally, the STAR tritium accountability database is discussed.

\section{INTRODUCTION}

The US Department of Energy (DOE) requires control and accountability of tritium down to $0.01 \mathrm{~g}$ (96 Ci) [2]. This paper provides a brief overview of tritium accountancy in the STAR facility. Hardware, calibration, data acquisition, data analysis, and the tritium accountability database are discussed.

The key tritium accountability systems at the STAR facility are the SAS, TCS, and STMS. The SAS utilizes pressure-volume-temperature (PVT) techniques to measure the quantity of tritium received into the facility and transferred to experiments. Tritium is not recovered from experiments and is sent either to the TCS or the facility stack. The TCS and STMS rely primarily on liquid scintillation counting (LSC) methods to quantify normal operational losses. Some experiments also use LSC for data analysis and accountancy functions.
Numerical analysis of the PVT and LSC data quantify the tritium transactions, and standard data reduction and analysis methods estimate the variance associated with each transaction. System functionality and calibration are essential to maintaining an accurate tritium inventory.

Tritium accountability operations require a minimum of two people. The lead scientist authorizes all tritium acquisitions and transfers. The nuclear material custodian (NMC) oversees tritium transfer operations and maintains the tritium accountability database. The lead scientist also reviews analytic methods and data, and has jurisdiction over hardware and calibration issues.

All tritium acquisitions, transfers, and normal operational losses are entered into a computerized tritium accountability database. The database provides a convenient listing of the values, uncertainties, and locations of all tritium sources in the facility.

\section{TRITIUM STORAGE AND ASSAY SYSTEM}

The SAS is designed to receive, assay, store, and dispense tritium to experiments [3]. The SAS relies on exact PVT measurements and a high purity tritium inventory to accurately determine tritium quantities. Tritium is stored in the SAS on two $47 \mathrm{~g}$ depleted uranium (DU) beds, each capable of holding $1.8 \mathrm{~g}$ $(\sim 17,300 \mathrm{Ci})$ of tritium. Other system components include a dry vacuum pump system, two calibrated volumes, 10 and 1000 torr pressure sensors, temperature sensors, a beta-scintillation detector (BSD), a quadrupole mass spectrometer (QMS), a metal bellows pump, electro-pneumatic and manual isolation valves, and interconnecting tubing. The system is operated with a computerized control and data acquisition system.

Calibration verification of the SAS pressure sensors is accomplished using a differential manometer which provides a means of correlating the manifold pressure to a calibration manometer. The accuracy of the pressure sensors are verified annually against manometers whose calibrations are traceable to National Institute for Standards and Technology (NIST) criteria. For the 10 torr sensors agreement with the calibration standard is $<0.5 \%$ over the pressure range. For the 1000 torr sensors 
agreement with the calibration standard is $<0.5 \%$ over the pressure range.

All segments in the SAS manifold were calibrated for volume by filling a calibration volume to a known pressure and then expanding the gas into regions of the system at constant temperature. At least five repetitions of the expansion tests were conducted. Standard data reduction and analysis methods were used to determine the uncertainty associated with each volume. The standard error associated the SAS manifold volume segments are generally $<2 \%$, although for some small segments the standard error is larger.

The SAS contains nine Omega Type-K thermocouples. Individual thermocouples are compared with others at essentially the same temperature to indirectly assess the accuracy of the readings. For Omega Type- $\mathrm{K}$ thermocouples above $0^{\circ} \mathrm{C}$ the limit of error is $2.2^{\circ} \mathrm{C}$ or $0.75 \%$ (whichever is greater).

The SAS is also equipped with a BSD and a QMS. The BSD is of limited usefulness in assaying high purity tritium samples, but the detector allows adequate measurement of tritium partial pressures in gas mixtures. The QMS is used to qualitatively identify impurities in tritium gas samples. These instruments are not used to adjust the tritium inventory.

Tritium accountability data analysis relies on accurate PVT measurements and a high purity tritium inventory. Therefore, only high purity tritium shipments are received into the SAS. DU bed to DU bed transfers are used to maintain the purity of the tritium inventory by removing ${ }^{3} \mathrm{He}$ decay products.

A computerized control and data acquisition system operates the SAS. Computer activated preset valve configurations combined with software and hardware inter-locks prevent unsafe operations. Tritium transactions are conducted using Operational Guidelines that were developed to ensure accurate tritium accountancy data. Each Operational Guideline has a corresponding Excel spreadsheet which calculates the quantity and variance of tritium transferred.

All tritium transactions are based on the ideal gas law and calculated using Eq. (1):

$$
\mathrm{A}=\left(58023 \mathrm{X}_{\mathrm{T}} \mathrm{PV}\right) /(\mathrm{RT})
$$

where $\mathrm{A}$ is the total activity, $\mathrm{T}_{2}$ gas contains 58023 $\mathrm{Ci} /$ mole [2], $\mathrm{X}_{\mathrm{T}}$ is the tritium concentration, and $\mathrm{P}$ is the pressure in volume $\mathrm{V}$ at temperature $\mathrm{T}$. $\mathrm{R}$ is the universal gas constant.

\section{TRITIUM CLEANUP SYSTEM}

The TCS was fabricated by M. Braun USA and is designed to remove tritiated species from glovebox atmospheres and process gas streams before the effluent is released to the facility exhaust [1]. The system utilizes a heated palladium catalyst bed $(\sim 18 \mathrm{~kg}$ of BASF-RO$25 / 50-0.5 \% \mathrm{Pd})$ to convert tritiated gas species into tritiated water, which is removed from the process steam by adsorption on molecular sieve beds. The de-tritiated effluent is then released to the facility exhaust. The TCS is equipped with redundant catalysts and molecular sieve beds. This arrangement allows for switchover to the backup component if an oxidizer fails or a molecular sieve bed is full and requires regeneration. Any tritiated species that make it past the TCS are released to the facility ventilation exhaust where they are accounted for with the STMS. The system is operated with a computerized control and data acquisition system.

During regeneration the molecular sieve beds are heated and the tritiated water is driven off and collected. The volume of water from regeneration is measured and the tritium activity concentration is assayed with a Packard model 2250CA liquid scintillation counter. The total tritium activity is the product of the tritium activity concentration and the volume of water collected. The maximum percent uncertainty associated with the TCS is estimated at $15 \%$. The tritiated water is a normal operational loss and is subtracted from the tritium accountability database when the waste leaves the facility.

\section{STACK TRITIUM MONITORING SYSTEM}

Tritium emissions from the STAR facility to the environment are monitored with the STMS. The STMS is comprised of a Mound Technical Solutions, Inc. model MRB500 Tritium Bubbler system and a Fan-Evaluator Air-Flow Measuring Station with a VELTRON-II readout manufactured by Air Monitor Corporation. A sample stream from the facility ventilation exhaust is directed to the MRB500 unit where the tritiated water in the sample stream is captured in a set of ethylene glycol filled bubblers. The sample stream then flows through a heated palladium catalyst bed which converts the remaining tritiated gas species into tritiated water that is captured in a second set of bubblers. Sample flow through the instrument is regulated with a precision mass flow controller. A bubble tube is used to verify the accuracy of the mass flow controller. A Packard model 2250CA liquid scintillation counter measures the tritium activity concentration in the bubblers. Volumetric airflow in the exhaust duct is measured using the Fan-Evaluator AirFlow Measuring Station and VELTON-II readout. Exhaust duct airflows are recorded daily. A VelociCalc Plus Air Velocity Meter (Model 8385A) hotwire anemometer manufactured by TSI Incorporated is used as reference for verifying the accuracy of the airflow measurements.

Sampling times are generally on the order of one week but can very depending on experiment activity. The 
total tritium emissions per sampling period can be calculated using Eq. 2:

$$
\mathrm{A}=\sum\left(\mathrm{CV}\left(\mathrm{F}_{\mathrm{E}} / \mathrm{F}_{\mathrm{B}}\right)\right)
$$

where $\mathrm{A}$ is the total activity, $\mathrm{C} \cdot \mathrm{V}$ is the product of the tritium activity concentration and the volume of liquid in each bubbler, and $F_{E} / F_{B}$ is the ratio of the average exhaust duct airflow to the sample flow through the MRB500 unit. Based on two years of operational experience, the average uncertainty in the STMS weekly emissions has been determined to be $11.2 \pm 5.6 \%$.

\section{TRITIUM ACCOUNTABILITY DATABASE}

The tritium accountability database provides a convenient listing of the values, uncertainties, and locations of all tritium sources in the facility. It is intended to ensure that facility tritium limits are not exceeded and also to address operational concerns such as tritium holdup. The database is in a spreadsheet format where the columns represent specific locations (or accounts) in the facility and the rows specific tritium operations. Each transaction in the database is identified by date and a brief description. The database is decay corrected prior to any inventory adjustments. Double entry accounting is used where positive values represent account additions and negative values represent account outputs or normal operating losses. Every tritium transaction is comprised of a value and its associated variance. Standard data reduction and analysis methods are used to estimate the variance associated with each transaction. The database keeps an accurate record of the total tritium inventory in the facility. However, correlating stack emissions with laboratory activities is difficult especially when multiple tritium operations are underway. This has no effect on the total tritium inventory, but leads to an increased uncertainty with regards to the quantity of tritium at specific locations in the STAR facility.

\section{CONCLUDING REMARKS}

STAR facility tritium accountancy involves personnel, hardware, calibration, operating procedures, and accounting processes. Diligence in these areas is essential to maintaining an accurate inventory. Infrastructure design features where tritiated species that pass through, or bypass, the TCS are accounted for with the STMS help to ensure the accuracy of the inventory. Increased tritium operations are expected to demonstrate that the tritium accountancy processes currently in place are fully capable of performing the tritium accountability requirements for the STAR facility.

\section{ACKNOWLEDGMENTS}

Work performed for U.S. Department of Energy, Office of Fusion Energy Sciences, under DOE-Idaho Operations Office Contract DE-AC07-05ID14517.

\section{REFERENCES}

1. R. A. Anderl, G. R. Longhurst, R. J. Pawelko, J. P. Sharpe, S. T. Schuetz, and D. A. Petti, "The Safety and Tritium Applied Research (STAR) Facility: Status-2004," Fusion Science and Technology, 48, 243, (2005).

2. DOE-HDBK-1129-99, Tritium Handling and Safe Storage," US Department of Energy (1999).

3. G. R. Longhurst, R. A. Anderl, R. J. Pawelko, and C. J Stoots, "Storage and Assay of Tritium in STAR," Fusion Science and Technology, 48, 332, (2005). 